NATIONAL LABORATORY

MANAGED BY UT-BATTELLE

FOR THE DEPARTMENT OF ENERGY

\title{
Roadmap to a Sustainable Structured Trusted Employee Program (STEP)
}

\section{August 2013}

Prepared by

Cameron W. Coates

Gerhard R. Eisele

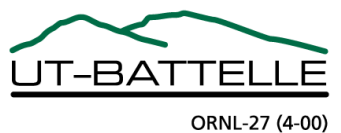




\section{DOCUMENT AVAILABILITY}

Reports produced after January 1, 1996, are generally available free via the U.S. Department of Energy (DOE) Information Bridge.

Web site http://www.osti.gov/bridge

Reports produced before January 1, 1996, may be purchased by members of the public from the following source.

National Technical Information Service

5285 Port Royal Road

Springfield, VA 22161

Telephone 703-605-6000 (1-800-553-6847)

TDD 703-487-4639

Fax 703-605-6900

E-mail info@ntis.gov

Web site http://www.ntis.gov/support/ordernowabout.htm

Reports are available to DOE employees, DOE contractors, Energy Technology Data Exchange (ETDE) representatives, and International Nuclear Information System (INIS) representatives from the following source.

Office of Scientific and Technical Information

P.O. Box 62

Oak Ridge, TN 37831

Telephone 865-576-8401

Fax 865-576-5728

E-mail reports@osti.gov

Web site http://www.osti.gov/contact.html

This report was prepared as an account of work sponsored by an agency of the United States Government. Neither the United States Government nor any agency thereof, nor any of their employees, makes any warranty, express or implied, or assumes any legal liability or responsibility for the accuracy, completeness, or usefulness of any information, apparatus, product, or process disclosed, or represents that its use would not infringe privately owned rights. Reference herein to any specific commercial product, process, or service by trade name, trademark, manufacturer, or otherwise, does not necessarily constitute or imply its endorsement, recommendation, or favoring by the United States Government or any agency thereof. The views and opinions of authors expressed herein do not necessarily state or reflect those of the United States Government or any agency thereof. 
Nuclear Security and Isotope Technology Division

\title{
ROADMAP TO A SUSTAINABLE STRUCTURED TRUSTED EMPLOYEE PROGRAM (STEP)
}

\author{
Cameron W. Coates \\ Gerhard R. Eisele
}

Date Published: August 2013

\author{
Prepared by \\ OAK RIDGE NATIONAL LABORATORY \\ Oak Ridge, Tennessee 37831-6283 \\ managed by \\ UT-BATTELLE, LLC \\ for the \\ U.S. DEPARTMENT OF ENERGY \\ under contract DE-AC05-00OR22725
}





\section{CONTENTS}

Page

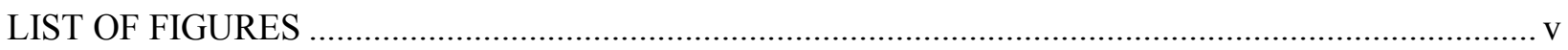

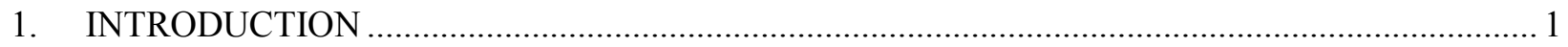

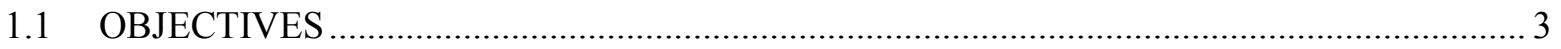

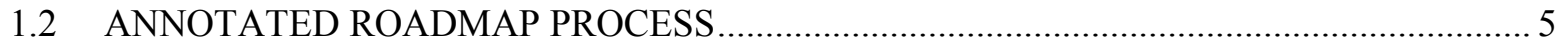

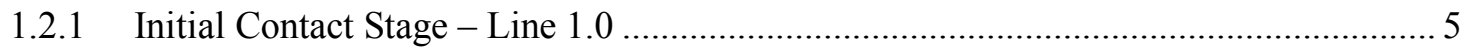

1.2.2 Implementation Team Formation Stage - Line 2.0 ............................................. 5

1.2.3 Work Guided by the STEP Implementation Team Terms of Reference....................... 5

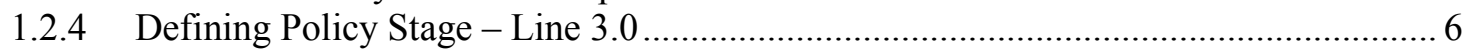

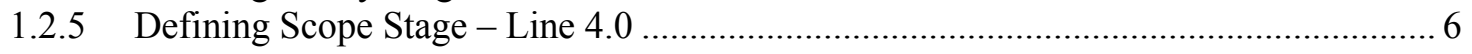

1.2.6 Selecting STEP Element and Preparing Procedures Stage - Line 5.0 ....................... 7

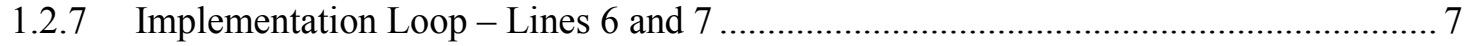

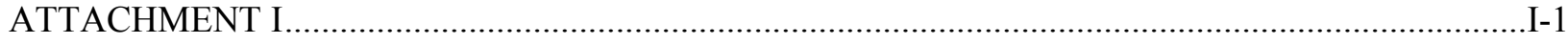

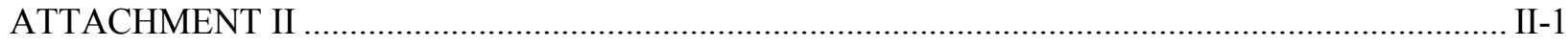





\section{LIST OF FIGURES}

Page

Fig. 1. Overlapping Programs at Sensitive Facilities................................................................. 1

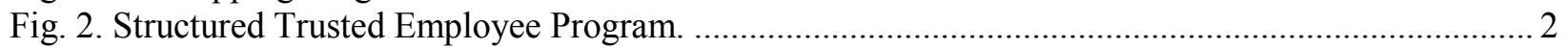

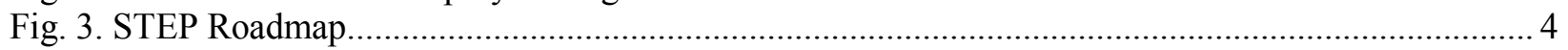

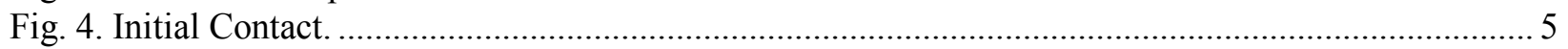

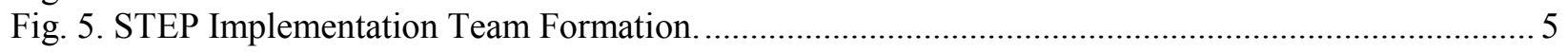

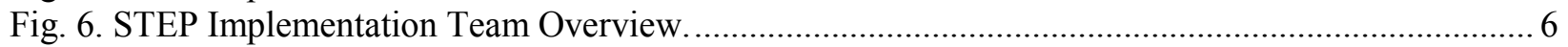

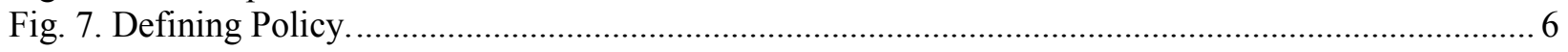

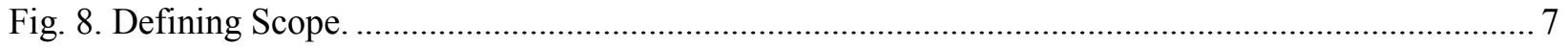

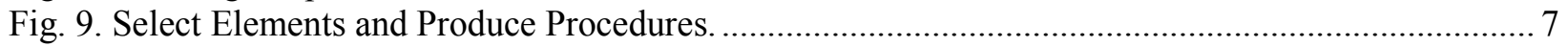

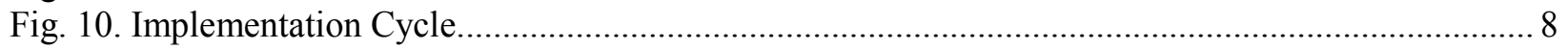





\section{INTRODUCTION}

Organizations (facility, regulatory agency, or country) have a compelling interest in ensuring that individuals who occupy sensitive positions affording access to chemical, biological, radiological, and nuclear (CBRN) materials facilities and programs are functioning at their highest level of reliability. Human reliability and human performance relate not only to security but also focus on safety. Reliability has a logical and direct relationship to trustworthiness, for the organization is placing trust in its employees to conduct themselves in a secure, safe, and dependable manner. The human factor is traditionally considered the weakest link in the security and safety process. Thus a program to encourage human reliability provides organizations with a process to help ensure that the highest quality employees are retained in these sensitive positions.

There is global concern to counteract insider threat; those with access to sensitive facilities can cause damage or harm the organization or CBRN facility. When looking at threats to an organization, there are a number of ways to separate areas of concern, organize a response, and mitigate threats. Figure 1 is a visual example of overlapping programs. Each element in Fig. 1 is interrelated to the other elements and has common, overlapping equities. Safety Culture in nuclear power plants (NPPs) is emphasized early in NPP development due to lessons learned from past safety violations and incidents which have resulted in a strong Safety Culture at NPPs. Safety Culture programs have been a longstanding focus for the nuclear industry, as with any industry handling dangerous materials. Security Culture programs are a relatively recent attempt to learn from the Safety Culture programmatic experiences and, as such, are playing catch up with Safety Culture programs. Security Culture and increased security postures are a direct result of increased threat levels experienced at nuclear facilities over the last decade or so.

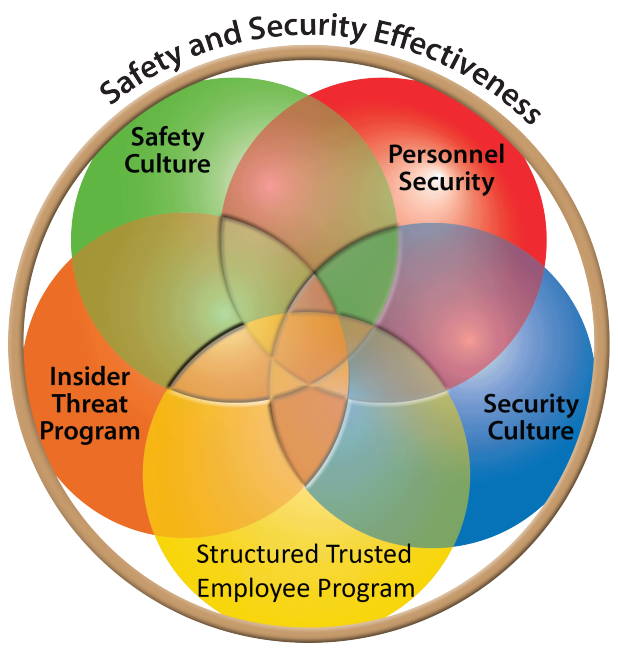

Fig. 1. Overlapping Programs at Sensitive Facilities.

Personnel Security, as differentiated from Physical Security (guns, guards and gates), focuses on issues that pertain to the worker and the corresponding risks. Personnel Security in the United States nuclear industry can be traced to the highly secretive Manhattan Project in which vetting (investigation and evaluation of the individual) and granting clearances (i.e., officially approving trustworthiness) was determined before access to sensitive information was given. The Department of Energy (DOE) Human Reliability Program (HRP) is the result of combining two existing but separate programs (one for nuclear security and the other for nuclear safety). The combination of these programs (Personnel Security Assurance Program and the Nuclear Explosive Safety Program) and the resulting DOE HRP are 
documented in the United States Code of Federal Regulations, Title 10, part 712 (10 CFR part 712). The realization that safety and security could be effectively interconnected began with the DOE HRP.

Insider Threat is rapidly becoming a significant area of concern for nuclear organizations. Programs to mitigate Insider Threat are gaining momentum as the number of insider incidents increases worldwide. An Insider Threat program interrelates with other elements of the Safety and Security Effectiveness "wheel" (Fig. 1), which is a construct to indicate that there are numerous overlapping elements at sensitive facilities which help ensure an effective program. These overlapping elements also include HRP, Security Culture, Personnel Security, and Safety Culture. The programs shown in Fig. 1 have significant areas of overlap and support each other in focus and methodology, but are not the same programs. Within this wheel is a Structured Trusted Employee Program (STEP), which is one tool inter alia mentioned that can be applied to mitigate a variety of risks. This report focuses on the implementation of a generic form of the DOE HRP, as identified earlier, called a STEP. The STEP process was developed by the Oak Ridge National Laboratory (ORNL) Center for Human Reliability Safety and Security Studies $\left(\mathrm{CHRS}^{3}\right)$. The $\mathrm{CHRS}^{3}$ and its associated Human Assurance Laboratory (HAL) were developed from a small program in 2005 to assist foreign organizations needing assistance in developing strict DOE-style HRPs. Over time the need for something more generic at facilities that did not need the stringent requirements of a DOEstyle HRP became apparent, and a more generalized STEP evolved.

This document focuses on providing an organization with a roadmap to implementing a successful and sustainable STEP. An overall view of the entire STEP process is shown in Fig. 2; however, each part of the process has significance and is defined and discussed in greater detail during training sessions, such as in the introduction workshop (Attachment I). It is important to note that STEP has an Initial Evaluation component that determines the eligibility of an individual to become a STEP employee. This Initial Evaluation is equivalent to the DOE clearance process. Once the individual is designated as a STEP employee, an ongoing evaluation loop is initiated (usually on an annual basis). Each major element of the continuing evaluation (Supervisor Review, Medical Evaluation, Management Decision, and Trust Official review) is defined by an organization's specific needs and size. Design of this process is conducted with the assistance of $\mathrm{CHRS}^{3}$ subject matter experts (SMEs) and is tailored to that organization.

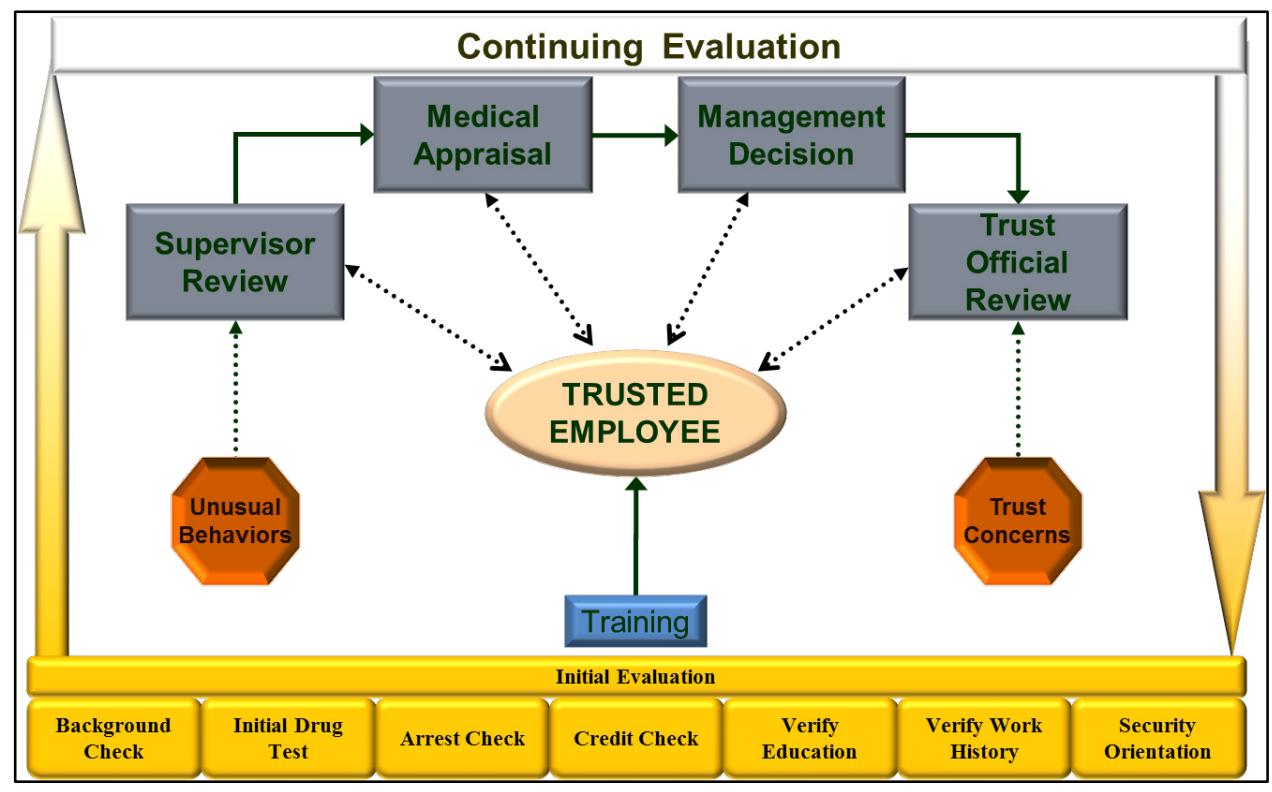

Fig. 2. Structured Trusted Employee Program. 


\subsection{OBJECTIVES}

The primary objective of a STEP is to ensure the security and safety of a facility by employing reliable and trustworthy individuals who can also recognize, report, and mitigate risks associated with unreliable individuals in sensitive positions. The organization can use a STEP to identify individuals who may present security and safety reliability concerns due to physical, mental/personality disorders, substance abuse, or other life circumstances. Finally an organization must develop comprehensive regulations, policies, and procedures which protect individual rights as well as the national security. Figure 3 describes a process that an organization can employ to begin the development of a STEP.

The STEP Roadmap in Fig. 3 begins with an Introduction to STEP (block 1.0) and its evolution from a DOE-style HRP. Workshops conducted by SMEs familiarize organization leadership with the basics of HRP/STEP as a fundamental first step. An agenda and topical outline for such a first workshop are provided in Attachment I. The key organization stakeholders and executives of an organization must first familiarize themselves with the STEP process before that organization can begin to implement a STEP using this roadmap. This includes an overview of program elements as used in other organizations with real-world examples to emphasize their relevancy. Once the organization decides to proceed with developing a STEP, an Executive Committee (EC) should establish a STEP Implementation Team comprised of organizational stakeholders and future implementers. The EC creates the Terms of Reference (TOR) (see Attachment II for a draft generic TOR). The purpose of the TOR is to identify for members of the EC the STEP elements that would be germane to their organization and to their nation's mores. Throughout this discussion process, additional or new elements may be identified for inclusion in the STEP.

The three columns in Fig. 3 represent Inputs (on the left), Processes (in the center), and Deliverables (on the right). Each block is numbered to identify its structural position within the process. 


\section{Structured Trusted Employee Program (STEP) Roadmap Flowchart}

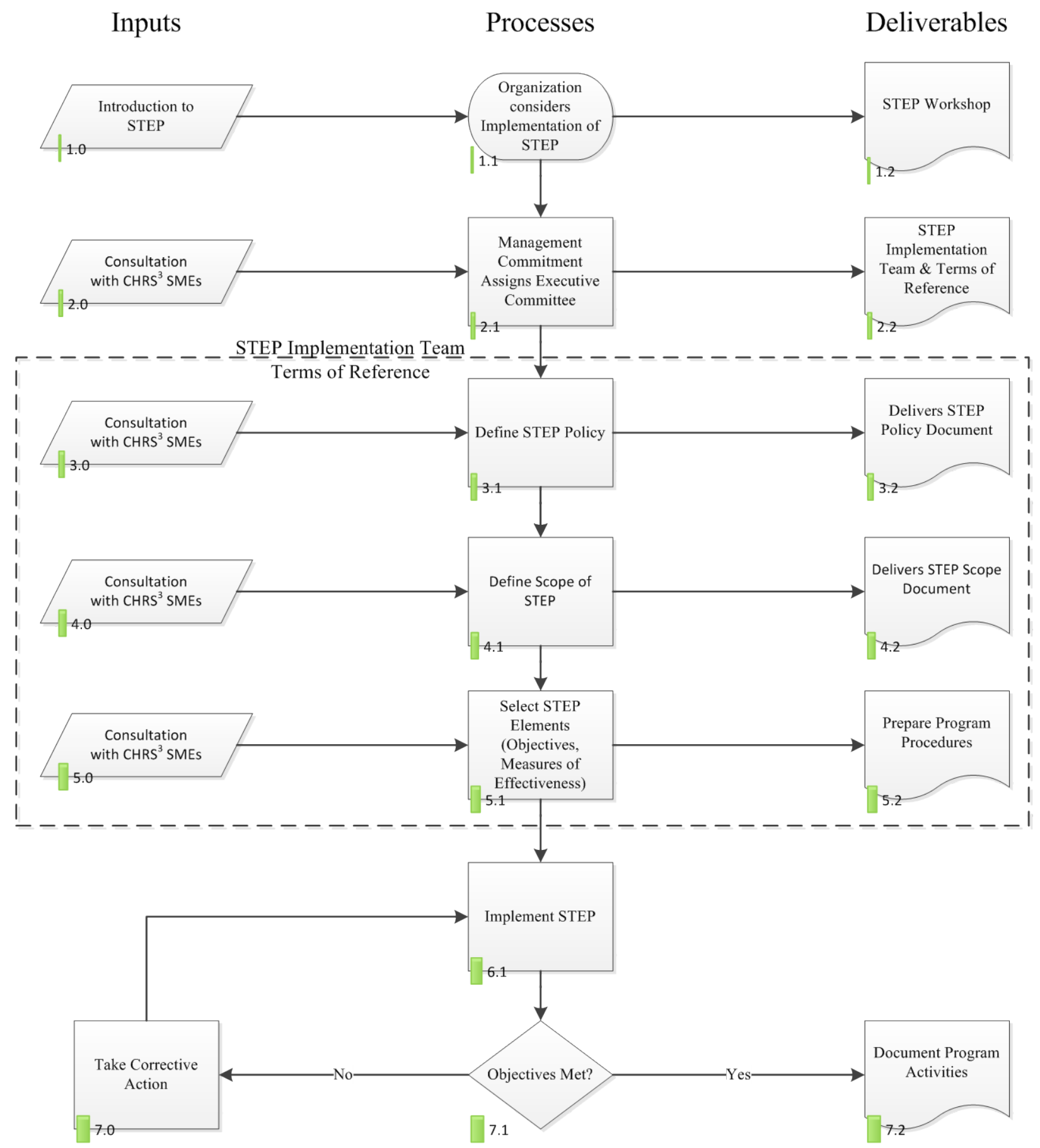

Fig. 3. STEP Roadmap. 


\subsection{ANNOTATED ROADMAP PROCESS}

\subsubsection{Initial Contact Stage - Line 1.0}

Figure 4 shows SME input to the management/leadership of an organization in which the STEP and Security Culture are discussed (1.0). The concepts resulting from this discussion are then brought to senior leadership for consideration (1.1). Input from outside groups can also provide valuable guidance during this phase of the process. A revised overview workshop (1.2) is then given to key stakeholders in the organization, as well as a high-level briefing to the senior management team (a key deliverable). These workshops can vary in length and are tailored to the organization's specific needs and interests but will generally take 3 to $3 \frac{1}{2}$ days onsite for a group of up to 25 individuals. A sample agenda is provided in Attachment I.

Inputs

Processes

Deliverables

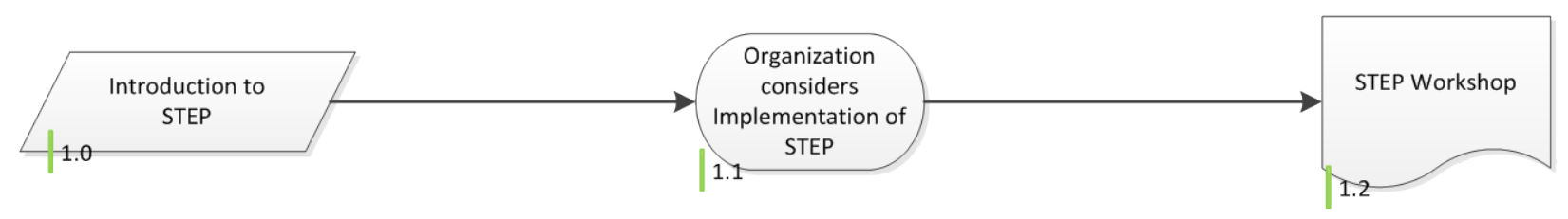

Fig. 4. Initial Contact.

\subsubsection{Implementation Team Formation Stage - Line 2.0}

Figure 5 represents the next stage after the organizational leadership has decided to begin the process of developing and implementing a STEP. This stage usually occurs after the workshop for stakeholders in the organization safety/security infrastructure has taken place. Management will select a group of key personnel to work closely with the SMEs to develop working documentation of a STEP tailored to the organization's overall culture and societal mores. The key deliverable at this stage is for the organization EC to create a Terms of Reference (TOR) for the STEP Implementation Team and select the members of the team (see Attachment II for a generic TOR).

Inputs $\quad$ Processes Deliverables

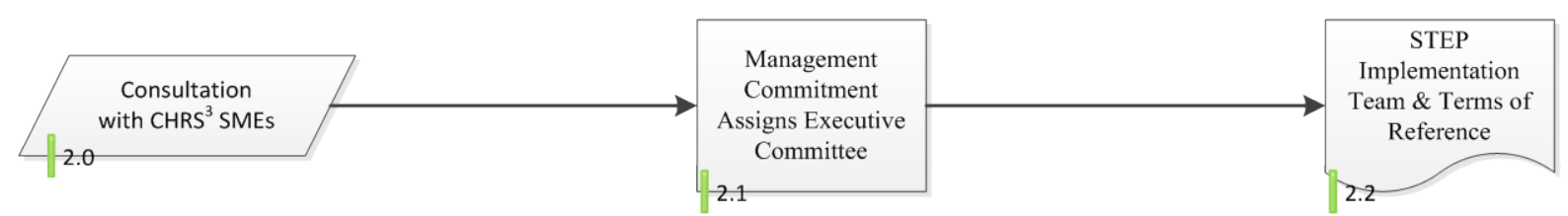

Fig. 5. STEP Implementation Team Formation.

\subsubsection{Work Guided by the STEP Implementation Team Terms of Reference}

An overview of the duties and responsibilities of the STEP Implementation Team is shown in Fig. 6. The STEP Implementation Team is central to a successful process and is responsible for providing a significant number of important deliverables to the EC for approval. (All deliverables are listed on the right side of Fig. 6.) General concepts for inclusion in the documents will be discussed below, but detailed discussion of the requirements from the CHRS ${ }^{3}$ SMEs is advisable before working outlines and draft documents are created. The work of the STEP Implementation Team relies heavily on SMEs who 
specialize in providing assistance with implementing a STEP. $\mathrm{CHRS}^{3}$ offers facilitation and guidance that allow the organization to determine solutions for their particular situation.
Inputs
Processes
Deliverables

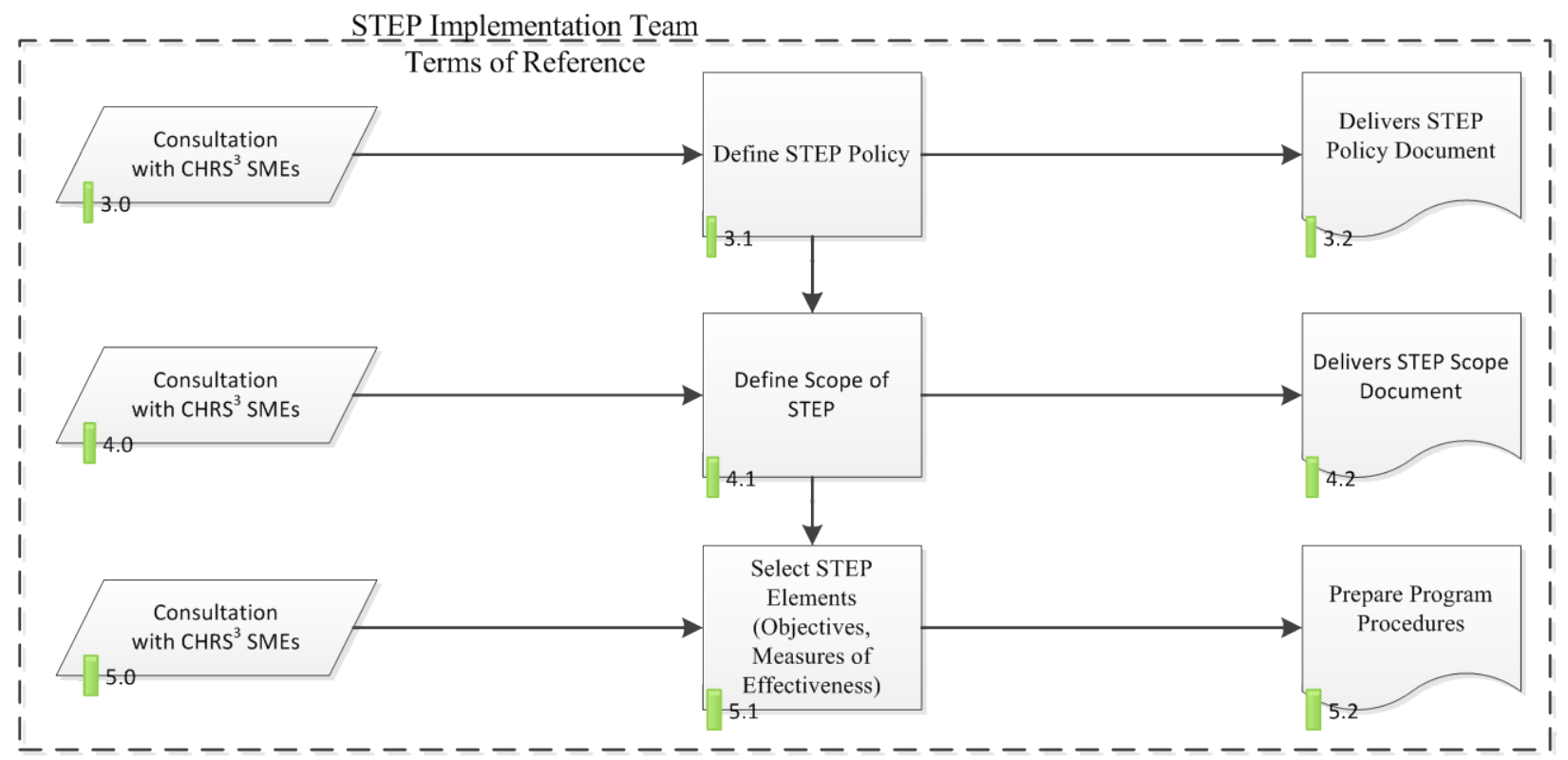

Fig. 6. STEP Implementation Team Overview.

\subsubsection{Defining Policy Stage - Line 3.0}

Policy is an executive-level issue; however, the STEP Implementation Team in conjunction with input from SMEs creates a draft policy document for EC review and approval, as shown in Fig. 7. The key deliverable is a policy-level document (3.2) that gives the organization direction in conducting a STEP. The Policy document should agree in format and content with other policy-level documents of the organization. This document provides the "Why" of the STEP for the organization's needs.

Inputs Processes Deliverables

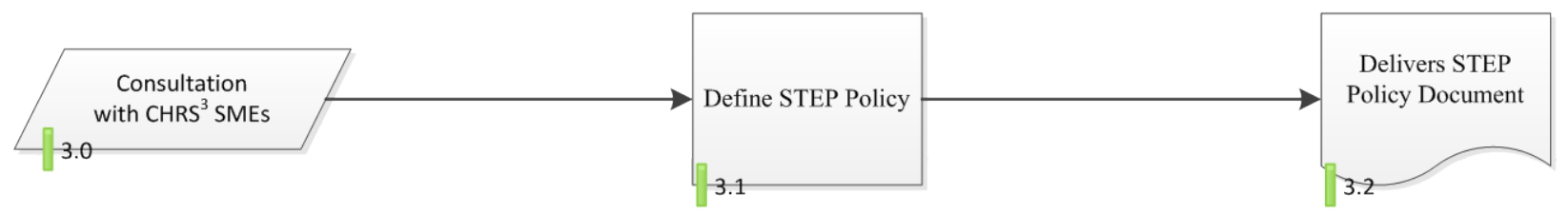

Fig. 7. Defining Policy.

\subsubsection{Defining Scope Stage - Line 4.0}

The next major deliverable for the STEP Implementation Team is a scope document, as shown in Fig. 8, which determines the full extent of the STEP (Who, What, When, and Where). This document describes the basis for determining who is in the STEP; the time length of the STEP continuing Evaluation loop; where the organization will manage the STEP; and the extent of the program elements needed. 
Inputs Processes Deliverables

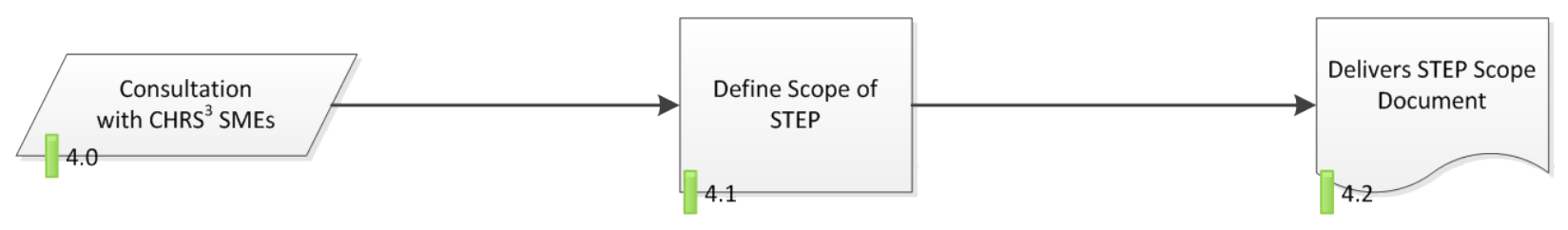

Fig. 8. Defining Scope.

\subsubsection{Selecting STEP Element and Preparing Procedures Stage - Line 5.0}

The next stage for the STEP Implementation Team, as shown in Fig. 9, is the development of a document that describes all regulatory requirements. The last and most important function of the STEP Implementation Team is to prepare program procedures that are available to the employees so that all can see that the program is being implemented fully and fairly. At this stage, all the elements have been selected and the objectives of the program and measures of effectiveness (MOEs) have been established.

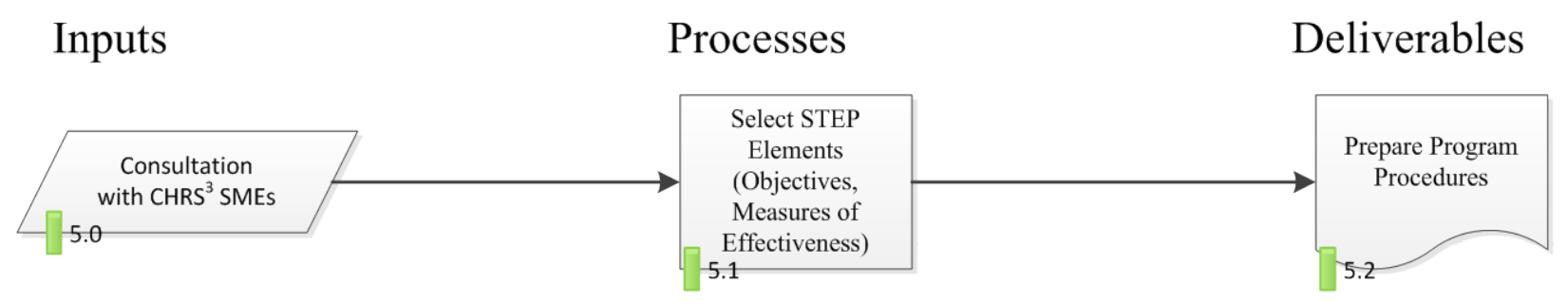

Fig. 9. Select Elements and Produce Procedures.

\subsubsection{Implementation Loop - Lines 6 and 7}

The Implementation of the STEP is not a static process, as shown in Fig. 10. The Implementation Team hands off the program to the organization and shepherds that organization during the first months of operation. The Implementation Team may also include some of the members of the organization who will eventually be responsible for the program and as such will develop a good rapport with the Implementation Team members, who will serve as references and mentors for several years. At this point the objectives are defined and MOEs have been established, and as such the STEP management organization can determine whether the objectives are being met on a periodic (and sometime immediate) basis. When it is determined that objectives are not being met and the MOEs are losing ground, corrective actions such as increased frequencies of testing or additional training may be required. Additionally, an outside audit and consultation with SMEs can point out weak points in the program. The corrective action varies with the seriousness of the objectives that are not met. 


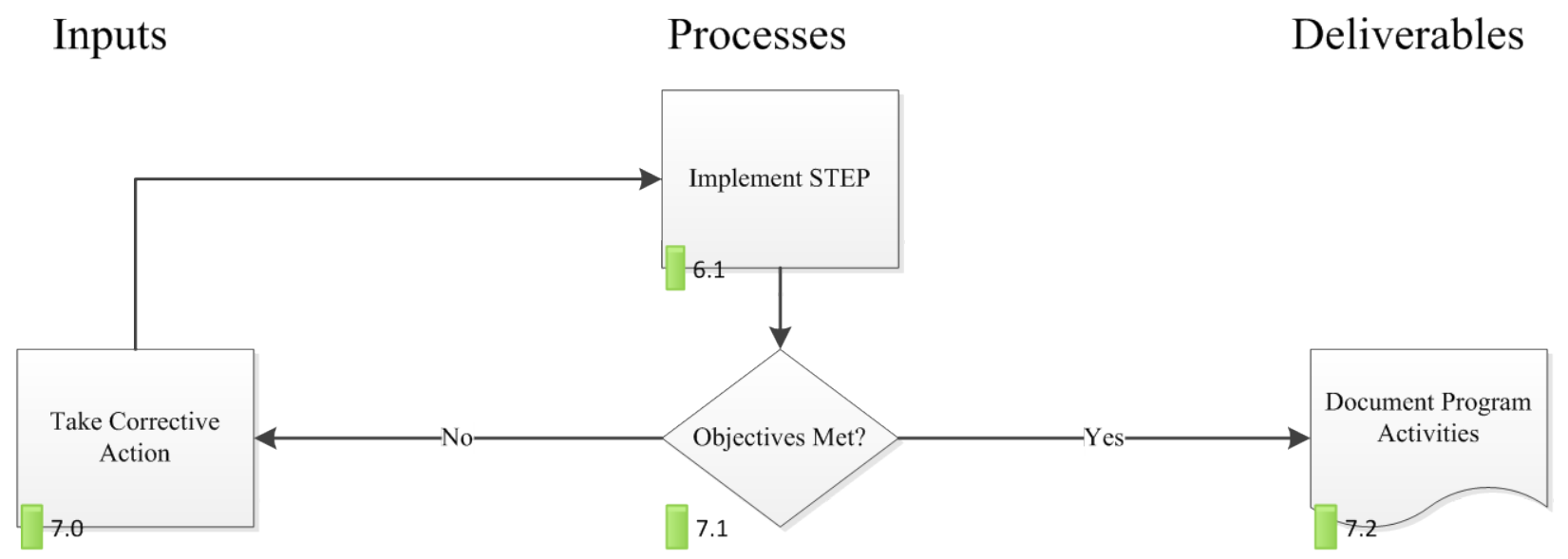

Fig. 10. Implementation Cycle.

The STEPs/HRPs are cyclical, and the cycle is repeated in the United States at DOE sites yearly. Other organizations may consider a shorter or longer cycle, but it is important to understand that people, circumstances, and influences change frequently and reevaluation needs to account for those possibilities. 


\section{ATTACHMENT I}

\section{Workshop on Establishing and Sustaining a Security Culture}

and Structured Trusted Employee Program (STEP)

Day 1

$8: 30$

9:00

$10: 15$

$10: 30$

12:00

13:00

$14: 15$

$14: 30$

$15: 45$

Day 2

9:00

9:45

10:15

10:30

11:15

12:00

13:00

14:15

14:30

15:45

Day 3

9:00

10:15

10:30

11:15

12:00
Welcome and Introductions

Host Organization(s)

Technical Implementers (ORNL)

Introduction to Security Culture and Human Reliability Programs (HRP) and STEP

Break

HRP/STEP Implementation and Sustainability

Lunch/Free Time

Supervisor Reviews

Break

Medical Reviews and Psychological Assessments

Day 1 Concludes

Management Reviews

Trust Official Reviews

Break

Critical Positions

Unusual Behavior Observation

Lunch/Free Time

Unusual Behavior Observation (Continued)

Break

Unusual Behavior Observation (Continued)

Day 2 Concludes

U.S. Security Evaluation Criteria Example for Pre-hire and Post-hired Staff

Break

Disgruntled Employee Identification and Employee Satisfaction

Insider Threat

Lunch/Free Time - End of Day for Participants 


\section{Briefing for Managers and Decision Makers on Security Culture and Trusted Employees}

13:00 Introduction to Security Culture and STEP

Supervisor Reviews

Medical and Psychological Assessments

Management Evaluation

Trust Official Reviews

14:30 U.S. Security Evaluation Criteria for Pre-hire and Post-hired Staff

15:45 Discussion Period

$\underline{\text { Day } 4}$

9:00 Review of Monday, Tuesday, and Wednesday Main Points

9:30 Case Studies

10:30 Facility Example

11:15 Break

11:30 Worksheet on Country's Training Needs

12:45 Group Workshop Concludes

\section{Background on Security Culture and STEP Trainers}

Oak Ridge National Laboratory (ORNL) Center for Human Reliability Safety and Security Studies $\left(\mathrm{CHRS}^{3}\right)$ staff have over 40 years of experience in development and implementation both domestically and internationally of security culture programs, Human Reliability Programs (HRP -US DOE style), Personnel Reliability Programs (PRP - US DoD style), and the aforementioned generic form of trusted employee program (STEP) for CBNE facilities worldwide. ORNL staff members are experts in the following:

- HRP/PRP/STEP policy development and analysis, including addressing potential insider risks associated with nuclear power plants and high value commodities

- Occupational medicine including fitness-for-duty requirements

- Substance abuse issues and concerns

- Developmental research and analysis in detection of deception

- Legal research related to security, reliability, and safety issues

- Workplace violence (disgruntled workers)

- Safety and security culture training 


\begin{tabular}{|c|c|c|}
\hline \multicolumn{3}{|c|}{ Available Structured Trusted Employee Program (STEP) Training Courses } \\
\hline Course Title & Duration & Description \\
\hline $\begin{array}{l}\text { Human Reliability Program } \\
(\text { HRP)/STEP Overview }\end{array}$ & $1-2$ hours & $\begin{array}{l}\text { Top-level overview for broad scientist, technician, and } \\
\text { engineer audiences of the general problem and the need } \\
\text { for trusted employees. Brief overview of STEP process } \\
\text { and its evolution from HRP. }\end{array}$ \\
\hline HRP/STEP Intro & 4 hours & $\begin{array}{l}\text { More detailed lectures for policy-level and program } \\
\text { managers touching the need for trusted employees. A bit } \\
\text { more detail on the STEP process than the overview for } \\
\text { scientists, technicians, and engineers. }\end{array}$ \\
\hline $\begin{array}{l}\text { STEP 0: Developing and } \\
\text { Implementing a STEP }\end{array}$ & $\begin{array}{l}2-3 \text { day } \\
\text { interactive } \\
\text { workshop }\end{array}$ & $\begin{array}{l}\text { This is a consolidated workshop combining the specific } \\
\text { elements listed as follows. The following topics } \\
\text { (STEP 1-STEP 8) can also be given as separate } \\
\text { interactive lectures. }\end{array}$ \\
\hline STEP 1: Introduction to HRP/STEP & $1-2$ hours & $\begin{array}{l}\text { Overview laying ground work for further discussions; } \\
\text { history of DOE HRP and evolution of generic STEP }\end{array}$ \\
\hline $\begin{array}{l}\text { STEP 2: Security Concerns Related to } \\
\text { Human Behavior }\end{array}$ & $1-2$ hours & $\begin{array}{l}\text { Details of human behavior and motivations (with } \\
\text { interactive discussion and examples) }\end{array}$ \\
\hline $\begin{array}{l}\text { STEP 3: Critical Position Selection } \\
\text { for STEP }\end{array}$ & $1-2$ hours & $\begin{array}{l}\text { Explanation of how to determine which employees } \\
\text { should be covered by STEP (with interactive discussion } \\
\text { and examples) }\end{array}$ \\
\hline $\begin{array}{l}\text { STEP 4: Medical Assessments as a } \\
\text { part of HRP }\end{array}$ & $1-2$ hours & $\begin{array}{l}\text { Details of medical criteria for evaluations (with } \\
\text { interactive discussion and examples) }\end{array}$ \\
\hline $\begin{array}{l}\text { STEP 5: Psychological Evaluations as } \\
\text { a part of STEP }\end{array}$ & $1-2$ hours & $\begin{array}{l}\text { Details of psychological evaluation process as a part of } \\
\text { the overall medical evaluation (with interactive } \\
\text { discussion and examples) }\end{array}$ \\
\hline $\begin{array}{l}\text { STEP 6: Unusual Behavior } \\
\text { Observation }\end{array}$ & $1-8$ hours & $\begin{array}{l}\text { Details of what constitutes unusual behavior and what to } \\
\text { do when observed (with interactive discussion and } \\
\text { examples) }\end{array}$ \\
\hline $\begin{array}{l}\text { STEP 7: Disgruntled Employee } \\
\text { Identification }\end{array}$ & $1-4$ hours & $\begin{array}{l}\text { How to identify disgruntled employees and the } \\
\text { associated risks (with interactive discussion and } \\
\text { examples) }\end{array}$ \\
\hline STEP 8: Insider Risks and STEP & $1-4$ hours & $\begin{array}{l}\text { Description of insider and insider capabilities; use of } \\
\text { case studies (with interactive discussion and examples) }\end{array}$ \\
\hline
\end{tabular}





\section{ATTACHMENT II \\ Structured Trusted Employee Program (STEP) \\ Implementing Team \\ TERMS OF REFERENCE (TOR)}

1. Role/Purpose

The Structured Trusted Employee Program (STEP) Implementing Team is created under the authority of the (INSERT NAME) Executive Committee (EC). The role of the EC is to provide the STEP Implementing Team with strategic direction and leadership that lead to a single unified management structure designed to ensure that individuals who occupy positions affording access to certain materials, facilities, and programs meet the highest standards of reliability and physical and mental suitability.

Granting STEP status shall include a determination that the individual is in what the Facility determines to be a Critical Position needing STEP status as defined by the STEP Implementing Team and approved by the EC. The initial evaluation for STEP status may include any of the following:

- Background check including references

- Initial substance abuse test

- Criminal arrest check

- Financial evaluation

- Education verification

- Employment verification

STEP elements that should be considered for inclusion into the STEP after an individual is granted STEP status include the following:

1. Supervisor Reviews (Annual)

2. Medical Reviews (Annual)

3. Management Reviews of $2 \& 3$ (including substance abuse testing)

4. Trust Official Reviews of $1,2, \& 3$ (final determination)

The (INSERT NAME) will ensure security and safety objectives through a system of continuous evaluation of individuals in STEP-designated positions to be determined by the committee.

2. Term

This Terms of Reference is effective from (INSERT START DATE) and continues until terminated by agreement between the parties.

3. Membership

The STEP Implementing Team will be comprised of designated persons from XXXXX and YYYYY:

- Name, Title, Organization 
- Name, Title, Organization

- Name, Title, Organization

- Name, Title, Organization

- Name, Title, Organization

- Name, Title, Organization

4. Roles and Responsibilities

(You will need to decide how your committee operates - some ideas are below)

The membership of the STEP Implementing Team will commit to the following:

1. attend all scheduled STEP Implementing Team meetings

2. share all relevant communications and information across all STEP Implementing Team members

3. make timely decisions and take action so as to not hold up progress

4. notify members of the STEP Implementing Team, as soon as practical, if any matter arises which may be deemed to affect the development of the Implementing Team

5. designate a proxy if unavailable

Members of the STEP Implementing Team will expect the following:

- to be provided with complete, accurate, and meaningful information in a timely manner

- to be given reasonable time to make key decisions

- to be alerted to potential risks and issues that could impact the committee, as they arise

- to participate in open and honest discussions, without resorting to any misleading assertions

- to receive ongoing "health checks" to verify the overall status and health of the committee

5. Meetings

All meetings will be chaired by (INSERT NAME AND ORGANIZATION)

Decisions made by consensus (i.e., members are satisfied with the decision even though it may not be their first choice). If not possible, the chair makes final decisions.

Meeting agendas minutes will be provided by (INSERT NAME AND ORGANIZATION); this includes

- preparing agendas and supporting papers and

- preparing meeting notes and information.

Meetings will be held (how often) for (specify time) at (specify location).

1. If required, subgroup meetings will be arranged at other times that are convenient to subgroup members.

6. Amendment, Modification, or Variation

This Terms of Reference may be amended or modified in writing after consultation and agreement by EC members. 
